\title{
COMBINING ABILITIES AND HETEROSIS OF BODY WEIGHT IN A DIALLEL CROSS FROM THREE SOUTH AFRICAN INDIGENOUS CHICKEN GENOTYPES
}

\author{
TYASI, T. L. ${ }^{1 *}-$ NORRIS, D. ${ }^{1}-$ NG'AMBI, J. W. ${ }^{1}-$ MABELEBELE, M. ${ }^{2}$ \\ ${ }^{1}$ Department of Agricultural Economics and Animal Production, University of Limpopo, Private \\ Bag X1106, Sovenga, Polokwane, South Africa \\ ${ }^{2}$ Department of Agriculture and Animal Health, College of Agriculture and Environmental \\ Sciences, University of South Africa, Pretoria, South Africa \\ *Corresponding author \\ e-mail: louis.tyasi@ul.ac.za \\ (Received $18^{\text {th }}$ Mar 2019; accepted $24^{\text {th }}$ May 2019)
}

\begin{abstract}
This study was conducted to estimate heterosis effects, specific and general combining abilities existing within growth traits. A $3 \times 3$ diallel mating system involved three indigenous chicken genotypes namely Potchefstroom Koekoek $(\mathrm{P})$, Venda $(\mathrm{V})$ and Ovambo $(\mathrm{O})$ was used to produce three purebreds $(\mathrm{P}$ $\mathrm{x} \mathrm{P}, \mathrm{V} \times \mathrm{V}, \mathrm{O} \times \mathrm{O})$, three crossbreds $(\mathrm{P} \times \mathrm{O}, \mathrm{P} \times \mathrm{V}, \mathrm{O} \times \mathrm{V})$ and three reciprocals $(\mathrm{O} \times \mathrm{P}, \mathrm{V} \times \mathrm{P}, \mathrm{V} \times \mathrm{O})$. The body masses of 225 chicks recorded at ages $0,4,8$ and 10 weeks, were used to make an estimation of heterosis, specific combining ability (SCA) and general combining ability (GCA). Results indicated that the crossbreed between $\mathrm{P}$ sires and $\mathrm{O}$ dams provided the uppermost heterosis for growth traits $(30.07 \%)$. GCA and SCA showed the importance $(\mathrm{P} \leq 0.05)$ for body weight from hatch up to 10 weeks of age. P genotype gave the positive effects of GCA and P x V crossbreed resulted in positive effects of SCA. It thus, be concluded that Potchefstroom Koekoek genotype might be used in the crossbreeding with other indigenous chicken genotypes to improve growth traits.
\end{abstract}

Keywords: Potchefstroom Koekoek, Venda, Ovambo, crossbred, purebred

\section{Introduction}

Indigenous chickens comprise about $80 \%$ of the national poultry flocks in Africa (Darre, 2012). Despite their importance, indigenous chickens have slow growth rates and relatively low mature weight (Norris and Ng'ambi, 2007). There are several indigenous chicken genotypes in South Africa (Malatji et al., 2016) including Potchefstroom Koekoek, Venda and Ovambo chicken genotypes. Potchefstroom Koekoek chicken genotype is a composite chicken genotype which was developed from three European poultry breeds namely White Leghorn, Black Australorp and Bared Plymouth Rock. This genotype is black and white speckled colour pattern, and was bred for both egg and meat production (Mutibvu et al., 2019). Ovambo chicken genotype is originated from Namibia and predominantly dark coloured that reach sexual maturity at $2.2 \mathrm{~kg}$ body weight for males and $1.5 \mathrm{~kg}$ for females at about 140 days old (Motsepe et al., 2016). Venda chicken genotype was first discovered in Venda region of Limpopo province, South Africa and is dual purpose, moderately large and multi-coloured predominated with white, black and red colours (Mphaphathi et al., 2016).

To date, in South Africa there is limited scientific information on crossbreeding of local chicken genotypes to improve growth traits. The aims of the study were to discover and underline the general combining abilities, heterotic effects and specific combining abilities for body weight in a three-way cross between Potchefstroom 
Koekoek, Ovambo and Venda chicken genotypes. According to Musa et al. (2015), crossing indigenous chicken genotypes has led to the improvement in growth rates and body weight. This study will help chicken farmers to determine the perfect combination of indigenous chicken genotypes during breeding program to improve body weight.

\section{Materials and methods}

\section{Study site}

The study was conducted at the same site described by Brown and Ng'ambi (2019). However, the current study was conducted between November 2012 and February 2013.

\section{House preparation}

Water disinfected with Jeyes fluid bought from a company in Polokwane called NTK was applied in hatchery and experimental houses. After, both hatchery and experimental houses were left to dry for 7 days to break the life cycle of possible disease caused by the organisms that were not killed by the disinfectant the houses were left empty for one week after cleaning. All the equipment such as feeders, wire separators and drinkers as well as the incubator were cleaned thoroughly and disinfected. New disinfectant was added daily and the footbath was thoroughly cleaned.

\section{Data collection}

Individual body weights of 180 chicks from a diallel cross of three indigenous chicken genotypes, namely Potchefstroom Venda (V), Koekoek (P) and Ovambo (O) were noted at the end of a week period from hatch up to 10 weeks of age. 10 hens from each genotype were allocated casually to be bred with two roosters of each genotype. Their eggs were gathered and noted down daily according to breeds and crossbreds. The eggs were weighed up and hatched independently according to breeds and crossbreds. Nine genetic groups of $\mathrm{P} \times \mathrm{P}, \mathrm{V} \times \mathrm{V}, \mathrm{O} \times \mathrm{O}, \mathrm{P} \times \mathrm{V}, \mathrm{P} \times \mathrm{N}, \mathrm{V} \times \mathrm{P}, \mathrm{V} \times \mathrm{O}, \mathrm{O} \times \mathrm{P}$, and $\mathrm{O} \times$ $\mathrm{V}$ chicks were obtained, accordingly. The hatched chicks were wing banded until 8 weeks of age followed by leg banding to keep their breed and crossbred group identity'. The chickens were reserved as a unit on a litter floor, in a semi-open house that has been separated according to their breeds and crossbreds. They were medicated equally and were subjected to the same climatic conditions managerial and hygienic. During the process of rearing periods and brooding, all chicks were fed ad-libitum using standard commercial starter $(21 \%$ crude, $3,000 \mathrm{kcal}$ and protein $(\mathrm{CP})$ metabolize capable energy $(\mathrm{ME}) / \mathrm{kg}$ ) from the time they hatched till they were four weeks, trailed by a cultivator diet $(2,900 \mathrm{kcal} \mathrm{ME} / \mathrm{kg}$ and $18 \% \mathrm{CP})$ to 62 days old. Water was provided ad-libitum. Artificial heat was provided at $\left(32^{\circ} \mathrm{C}\right)$ using continuous light program and ultraviolet lights were provided. Ventilation was controlled through curtain rails.

\section{Statistical analysis}

The effect of genetic group on body weight was tested using the general linear model (GLM) procedure of Statistical Analysis System software program (SAS, 2008). Duncan's multiple range test was used for significant means at $\mathrm{P}<0.05$. The following model was used:

$$
\mathrm{Y}_{\mathrm{ij}}=\mu+\mathrm{G}_{\mathrm{i}}+\mathrm{e}_{\mathrm{ij}}
$$


where $Y_{i j}=$ body weight of bird in $i^{\text {th }}$ genetic group, $\mu=$ overall mean, $G_{i}=$ fixed effect of the $\mathrm{i}^{\text {th }}$ genetic group and $\mathrm{e}_{\mathrm{ij}}=$ random error.

Heterosis was calculated according to Fairfull (1990) and the following formula was applied:

$$
\mathrm{H} \%=\left[\frac{\mathrm{AB}(0.5 \mathrm{AA}+0.5 \mathrm{BB})}{(0.5 \mathrm{AA}+0.5 \mathrm{BB})}\right] \times 100
$$

where $\mathrm{H} \%=$ percentage heterosis, $\mathrm{AB}=$ crossbred genotype, $\mathrm{AA}$ and $\mathrm{BB}=$ sire and dam genotypes. General and specific combining abilities were calculated in the form of means (Falconer, 1988). The following formulas were used:

$$
\begin{aligned}
& \text { Specific combining ability }(\mathrm{SCA})=\frac{\mathrm{AB}+\mathrm{BA}}{2} \\
& \text { General combining ability }(\mathrm{GCA})=\frac{\mathrm{A}+\mathrm{GCA}(\mathrm{B})}{2}
\end{aligned}
$$

where $\mathrm{AB}=$ cross between genotype $\mathrm{A}$ and $\mathrm{B}$, and $\mathrm{BA}=$ its reciprocal.

\section{Results}

\section{Body weight at different weeks of age}

The results showed body weights at different weeks of age differed significantly $(\mathrm{P}<0.05)$ among the nine genetic groups (Table 1). Least square means showed that Potchefstroom Koekoek (P) and Ovambo (O) had higher hatch weight (30 g) followed by $\mathrm{P} x \mathrm{~V}$ and $\mathrm{V}$ x O with $29.60 \mathrm{~g}$, and $\mathrm{O}$ x V (28.80 g), respectively. Nonetheless, there was no substantial variance $(\mathrm{P}>0.05)$ between $\mathrm{P} \times \mathrm{O}, \mathrm{O} \times \mathrm{V}$ and $\mathrm{V} \mathrm{X} \mathrm{P}$ at hatch, with body weights of 27.60, 28.80 and $28 \mathrm{~g}$. Results also indicated that Venda chickens performed better in body weight when crossed with Ovambo in comparison with other crosses during the hatch period. For purebreds, Ovambo and Potchefstroom Koekoek were heavier $(30 \mathrm{~g})$ than the Venda chickens $(20 \mathrm{~g})$ at hatch. For crosses, the $\mathrm{P} \times \mathrm{V}$ was heavier $(29.60 \mathrm{~g})$ when compared to $\mathrm{O} \times \mathrm{V}$ and $\mathrm{P}$ x O which their body weight was $27.60 \mathrm{~g}$ also $28.80 \mathrm{~g}$, respectively. For purebreds, Potchefstroom Koekoek had a heavier body weight $(256 \mathrm{~g})$ as compared to other purebreds in the fourth week. There were no differences in the fourth week, $(\mathrm{P}>0.05)$ among the Ovambo purebred, $\mathrm{V} \times \mathrm{P}$ and $\mathrm{O} \times$ $\mathrm{V}$. With respect to crosses, $\mathrm{P} \times \mathrm{O}$ had a higher body weight (256 g) in compared to the $\mathrm{O} \times \mathrm{V}$ and $\mathrm{P} \times \mathrm{V}$ which their weights were of 255.92 and $232 \mathrm{~g}$, respectively. Among the reciprocals, $\mathrm{O} \times \mathrm{P}$ body weighed higher $(276 \mathrm{~g})$ in comparison with the $\mathrm{V} \times \mathrm{O}$ and $\mathrm{V}$ $\mathrm{x} P$ which weighed $232 \mathrm{~g}$ and $244 \mathrm{~g}$, respectively.

\section{Heterosis}

Heterosis results (Fig. 1) with respect to crosses showed that $\mathrm{O} \times \mathrm{V}$ had affirmative heterosis in all different ages. $\mathrm{P} \times \mathrm{O}$ had positive heterosis from hatching to 4 weeks of age only and afterwards had negative heterosis while $\mathrm{P} \times \mathrm{V}$ had positive heterosis at all different ages apart from 10 weeks of age, respectively. With deference to reciprocals, the $\mathrm{V} \times \mathrm{P}$ had positive heterosis at all ages whereas the $\mathrm{O} \times \mathrm{P}$ exhibited negative heterosis at all ages of measurement except 4 weeks of age, respectively. $\mathrm{V}$ x $\mathrm{O}$ showed 
positive heterosis at hatching and four weeks of age and indicated negative heterosis at 8 weeks and 10 weeks of age.

Table 1. Least squares means for body weight ( $g$ ) from hatch up to 10 weeks during different age intervals for purebreds, reciprocals and crosses

\begin{tabular}{|c|c|c|c|c|c|}
\hline \multirow{2}{*}{ Genetic groups } & \multirow{2}{*}{ Number of chicks } & \multicolumn{4}{|c|}{ Age (week) } \\
\hline & & Hatch & BW4 & BW8 & BW10 \\
\hline \multicolumn{6}{|l|}{ Purebreds } \\
\hline $\mathrm{P} \times \mathrm{P}$ & 25 & $30.00^{\mathrm{a}}$ & $256.00^{\mathrm{b}}$ & $800.00^{\mathrm{d}}$ & $1366.67^{b}$ \\
\hline $\mathrm{O} \times \mathrm{O}$ & 25 & $30.00^{\mathrm{a}}$ & $232.00^{\mathrm{e}}$ & $1000.00^{\mathrm{a}}$ & $1233.33^{\mathrm{d}}$ \\
\hline $\mathrm{V} \times \mathrm{V}$ & 25 & $20.00^{\mathrm{d}}$ & $204.00^{\mathrm{f}}$ & $630.00^{\mathrm{g}}$ & $1000.00^{\mathrm{h}}$ \\
\hline \multicolumn{6}{|l|}{ Crosses } \\
\hline $\mathrm{P} \times \mathrm{O}$ & 25 & $27.60^{b}$ & $256.00^{b}$ & $800.00^{\mathrm{d}}$ & $1280.00^{c}$ \\
\hline$P \times V$ & 25 & $29.60^{\mathrm{a}}$ & $255.92^{\mathrm{c}}$ & $770.00^{\mathrm{e}}$ & $1133.33^{\mathrm{f}}$ \\
\hline $\mathrm{O} \times \mathrm{V}$ & 25 & $28.80^{\mathrm{ab}}$ & $232.00^{\mathrm{e}}$ & $830.00^{c}$ & $1133.33^{\mathrm{f}}$ \\
\hline \multicolumn{6}{|l|}{ Reciprocals } \\
\hline $\mathrm{O} \times \mathrm{P}$ & 25 & $21.60^{c}$ & $276.00^{\mathrm{a}}$ & $800.00^{\mathrm{d}}$ & $1166.67^{\mathrm{e}}$ \\
\hline$V \times P$ & 25 & $28.00^{\mathrm{b}}$ & $232.00^{\mathrm{e}}$ & $930.00^{\mathrm{b}}$ & $1433.33^{\mathrm{a}}$ \\
\hline $\mathrm{V} \times \mathrm{O}$ & 25 & $29.60^{\mathrm{a}}$ & $244.00^{\mathrm{d}}$ & $700.00^{f}$ & $1033.33^{\mathrm{g}}$ \\
\hline
\end{tabular}

${ }^{a-g}$ Least square means in the same column with different superscripts differ significantly $(\mathrm{P}<0.05)$ $\mathrm{P}=$ Potchefstroom Koekoek, $\mathrm{V}=$ Venda and $\mathrm{O}=$ Ovambo.

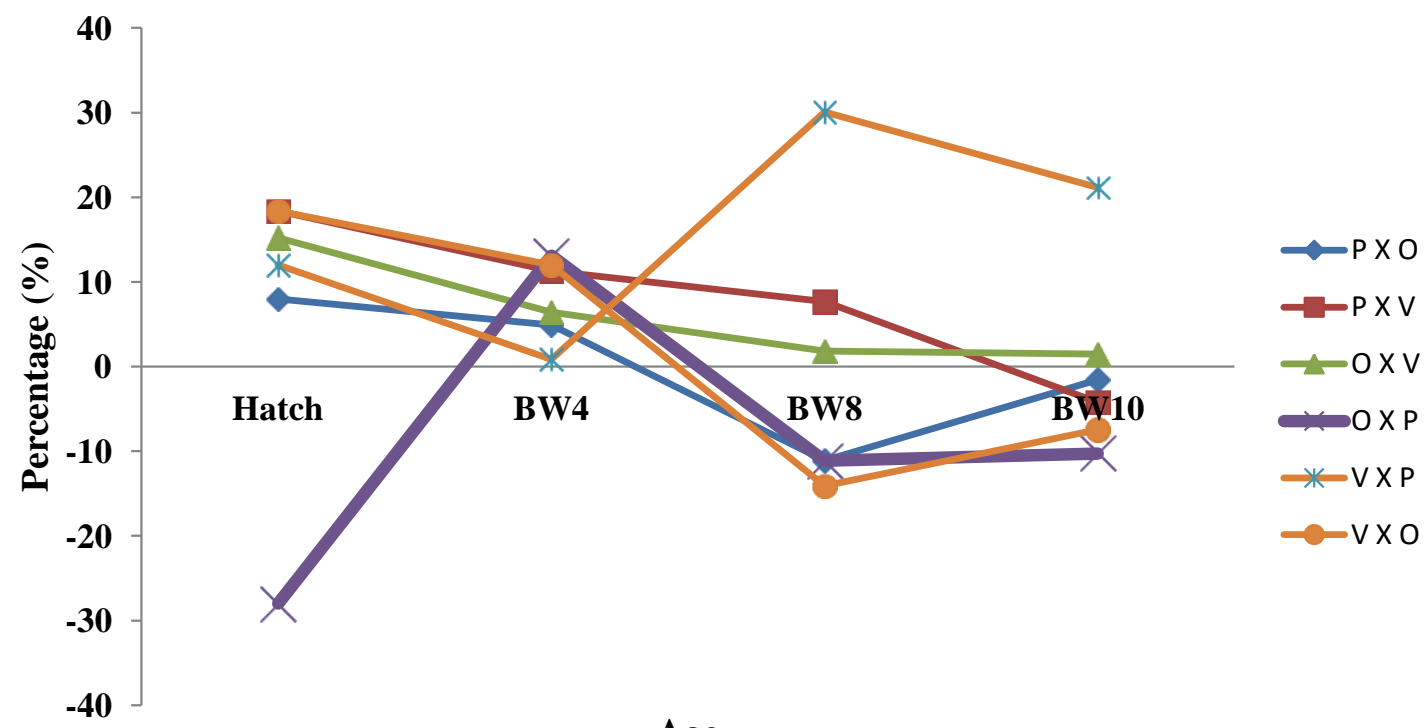

Age

Figure 1. Heterosis percentages for body weight at different ages. $P X O, P X V$ and $O X V$ are the crosses between Potchefstroom Koekoek sire and Ovambo dam, Potchefstroom Koekoek sire and Venda dam, and Ovambo sire and Venda dam, respectively. $O X P, V X P$ and $V X O$ are the reciprocals between Ovambo sire and Potchefstroom Koekoek dam, Potchefstroom Koekoek dam and Venda sire, and Ovambo dam and Venda sire. $X$ indicates the cross between genotypes. Hatch is the body weight after hatching, BW4 is body weight at four weeks, BW8 is body weight at eight weeks and BW10 is a body weight at ten weeks of age. 


\section{Combining abilities}

SCA effects and estimates of GCA are presented in Table 2. GCA showed that the P breed had positive effects during the studied periods. However, $\mathrm{O}$ genotype had a positive effect during the studied ages, except at 10 weeks of age. The Venda genotype had the lowest negative estimates at all stages of growth. SCA showed that the $\mathrm{P} \times \mathrm{O}$ crossbred had negative effect at hatch, 8 weeks and 10 weeks of age, and a positive effect at 4 weeks of age in comparison among crossbreds. $\mathrm{P} \times \mathrm{V}$ crossbred gave positive effects at all different ages. $\mathrm{O} x \mathrm{~V}$ crossbred had positive effects at hatch and at 4 weeks of age; however, it showed negative effects at 8 weeks and 10 weeks, respectively.

Table 2. Crossbreeding genetic parameters for body weight at different ages of measurement

\begin{tabular}{c|c|c|c|c}
\hline Parameters & Hatch & 4 weeks & 8 weeks & 10 weeks \\
\hline General combining abilities & \multicolumn{4}{|l}{} \\
\hline g & 0.56 & 12.22 & 10.00 & 93.34 \\
$\mathrm{~g}$ & 0.69 & 2.23 & 48.33 & -17.78 \\
$\mathrm{~g}$ V & -1.24 & -14.45 & -58.33 & -75.56 \\
\hline Specific combining abilities & -3.89 & 8.45 & -65.00 & -50.00 \\
\hline sO & 2.24 & 3.09 & 91.67 & 67.78 \\
s & 2.51 & 7.12 & -31.67 & -21.11 \\
s &
\end{tabular}

$\mathrm{g}=$ general combining ability, $\mathrm{s}=$ specific combining ability.

\section{Discussion}

This study was directed to investigate heterosis, specific combining abilities and general combining abilities for body weight traits after crossing three South African indigenous chicken genotypes; namely Potchefstroom Koekoek, Venda and Ovambo. Our results based on cross for heterosis, the effects for body weights were mostly positive and ranged from -14.11 to $30.07 \%$ during different age intervals up to 10 weeks of age. However, Musa et al. (2015) reported that heterosis for body weight ranged from -9.44 to $13.48 \%$ after crossing three genotypes of Nigerian indigenous chickens. Results of the current study revealed that the $\mathrm{P} \times \mathrm{V}$ cross had encouraging heterosis at all different ages of measurement except at 10 weeks of age when compared to its reciprocal $\mathrm{V} \times \mathrm{P}$, that had positive heterosis at all ages and highest 10 weeks of age. The $\mathrm{O} \times \mathrm{V}$ had positive low heterosis for body weight at the different weeks of age when compared to its reciprocal $\mathrm{V} \times \mathrm{O}$ which had negative heterosis for body weight at all weeks of measurement except at hatch and 4 weeks of age. These findings indicate that Potchefstroom Koekoek sires and Ovambo dams as well as Venda and Venda sires gave the highest heterosis for growth traits. Furthermost reviewed studies showed that body weights of crossbred chickens at different ages were related with negative and positive heterosis effects for growth traits (Sutherland et al., 2018; Musa et al., 2015; Siwendu et al., 2012). However, Nwenya et al. (2017) reported a positive heterosis for body weight after crossing Naked neck and Frizzled feather chickens. Our heterosis results might stand as an encouraging element for the poultry breeders in South Africa to cross these two breeds (Venda female and Potchefstroom Koekoek male) and (Ovambo female and Venda male) to get hybrid vigour in growth traits. Furthermore, we also estimated the general combining abilities and specific combining abilities among purebreds and 
crosses of South African indigenous chicken genotypes. General combining ability (SCA) was a significant source of variability among purebred groups on body weights at different growth stages. This importance showed the importance of preservative components. These results are similar with the work of Musa et al. (2015), who found general combining ability estimations more significant and of higher in three genotypes of Nigerian indigenous chickens. Adebambo et al. (2010) reported the significant of GCA for body weight using three chicken genotypes. Our findings recognized that Potchefstroom Koekoek chicken genotype had the uppermost (best) encouraging effect of general combining ability at all ages of measurement excluding at hatch and 8 weeks of age while the Venda breed had negative effect at all ages. Specific combining ability results point out that $\mathrm{P} \times \mathrm{V}$ provided positive estimates for body weight throughout the different weeks of measurement. This cross could be recommended for the future. In addition, $\mathrm{P} \times \mathrm{O}$ had high negative estimates for body weight at all the ages of measurement except for 4 weeks of age.

\section{Conclusion}

Diallel cross mating system was performed in three South African indigenous chicken genotypes to estimate crossbreeding parameters. Heterosis estimations indicate that crosses between the Venda dams and Potchefstroom Koekoek sires as well as between the Ovambo dams and Venda sires provided the highest heterosis effect for body weight. It might be significant to contemplate developing a composite chicken genotype based on the estimations of heterosis, specific combining ability and general combining ability. The current study has shown the significance of bearing in mind the estimates of heterosis effects, general combining ability and specific combining ability effect before planning any crossbreeding program.

\section{REFERENCES}

[1] Adebambo, A. O., Ikeobi, C. O. N., Ozoje, M. O., Oduguwa, O. O., Adebambo, O. A. (2010): Combining abilities of growth traits among pure and crossbred meat type chickens. - Architecture Zoo Technology 60: 953-963.

[2] Brown, D., Ng'ambi, J. W. (2019): Effects of dietary vachelia karrooleaf meal inclusion on meat quality and histological parameters in Pedi bucks fed a setaria verticillatahaybased diet. - Applied Ecology and Environmental Research 17(2): 2893-2909.

[3] Darre, M. J. (2012): The Importance of Poultry in Our Lives. - Department of Animal Sciences, University of Connecticut, Storrs, CT.

[4] Fairfull, R. W. (1990): Heterosis. - In: Crawford, R. D. (ed.) Poultry Breeding and Genetics. Elsevier, Amsterdam, pp. 913-933.

[5] Falconer, D. S. (1988): Introduction to Quantitative Genetics. - John Wiley and Sons, New York.

[6] Malatji, D. P., Tsotetsi, A. M., van Marle-Koster, E., Muchadeyi, F. C. (2016): A description of village chicken production systems and prevalence of gastrointestinal parasites: Case studies in Limpopo and KwaZulu-Natal provinces of South Africa. Onderstepoort Journal of Veterinary Research 83(1): 1-8.

[7] Motsepe, R., Mabelebele, M., Norris, D., Brown, D., Ngambi, J., Ginindza, M. (2016): Carcass and meat quality characteristics of South African indigenous chickens. Biological and Biotechnological Sciences 50(4): 580-587. 
[8] Mphaphathi, M. L., Seshoka, M. M., Luseba, D., Sutherland, B., Nedambale, T. L. (2016): The characterization and cryopreservation of Venda chicken semen. - Asian Pacific Journal of Reproduction 5(2): 132-139.

[9] Musa, A. A., Orunmuyi, M., Akpa, G. N., Olutunmogun, A. K., Muhammad, H., Adedibu, I. I. (2015): Diallel analysis for body weight involving three genotypes of Nigerian indigenous chickens. - South African Journal of Animal Science 45(2): 188197.

[10] Mutibvu, T., Chimonyo, M., Halimani T. E. (2019): Effect of strain, sex and rearing system on carcass and fat yield of Naked Neck, Ovambo and Potchefstroom Koekoek chickens. - Indian Journal of Animal Research. DOI: 10.18805/ijar.B-944.

[11] Norris, D., Ng'ambi, J. W. (2007): Genetic parameter estimates for body weight in local Venda chickens. - Tropical Animal Health Production 38: 7-8.

[12] Nwenya, J. M., Nwakpu, E. P., Nwose, N. R., Ogbuagu, P. K. (2017): Performance and heterosis of indigenous chicken crossbreed (Naked Neck x Frizzled Feather) in the humid tropics. - Journal of Poultry Research 14(2): 07-11.

[13] SAS (2008): User Guide: Statistics Release 9.2. - Statistical Analysis System Institute, Inc., Cary, North Caroline.

[14] Siwendu, N. A., Norris, D., Ng'ambi, J. W., Shimelis, H. A., Benyi, K. (2012): Heterosis and combining ability for body weight in a diallel cross of three chicken genotypes. Tropical Animal Health Production 20: 23-25.

[15] Sutherland, D. A. T., Honaker, C. F., Dorshort, B., Anderson, L., Siegel, P. B. (2018): Asymmetries, heterosis and phenotypic profiles of red junglefowl, White Plymouth Rocks, and $F_{1}$ and $F_{2}$ reciprocal crosses. - Journal of Applied Genetics 59(2): 193-201. 